\title{
Serum $\beta$-Defensin-2 Levels and Their Relationship with the Clinical Course and Prognosis in Patients with Crimean-Congo Hemorrhagic Fever
}

\author{
Osman Aksoy ${ }^{\mathrm{a}}$ Emine Parlak ${ }^{\mathrm{b}}$ Mehmet Parlak ${ }^{\mathrm{b}}$ Hülya Aksoy \\ ${ }^{a}$ Balıklı Göl State Hospital, Urfa, and Departments of ${ }^{\mathrm{b}}$ Infectious Diseases and Clinical Microbiology and \\ ${ }^{c}$ Medical Biochemistry, Faculty of Medicine, Atatürk University, Erzurum, Turkey
}

\section{Key Words}

Antimicrobial peptide · Crimean-Congo hemorrhagic fever . $\beta$-Defensin-2 $\cdot$ Hemophagocytic syndrome

\begin{abstract}
Objective: The aim of this study was to investigate the role of the clinical course and prognosis of serum levels of $\beta$-defensin-2 (BD-2) in patients with Crimean-Congo hemorrhagic fever (CCHF). Subjects and Methods: Patients who were hospitalized in the Department of Infectious Diseases and Clinical Microbiology of the Faculty of Medicine, Ataturk University, were considered for inclusion in this study. The patients had positive real-time reverse transcription polymerase chain reaction and/or enzyme-linked immunosorbent assay results of the CCHF virus. There were 60 patients with CCHF in the study group and 25 healthy participants in the control group. Serum BD-2 levels were measured using ELISA. Data were analyzed using the Student $t$ test or MannWhitney U test. Results: Of the 60 patients, 6 (10\%) died and $54(90 \%)$ were discharged following their recovery. The mean BD-2 level of the patient group was significantly higher $(4,180.30 \pm 3,944.19 \mathrm{pg} / \mathrm{ml})$ than that of the control group $(964.45 \pm 266.07 \mathrm{pg} / \mathrm{ml} ; \mathrm{p}=0.001)$. Serum BD-2 levels of the patients with fatal $(1,529.81 \pm 1,028.14)$ and nonfatal disease $(4,474.80 \pm 4,041.58)$ differed, but this difference showed
\end{abstract}

only borderline significance $(p=0.055)$. The mean BD-2 level of the severe group was $5,507.45 \pm 4,327.06 \mathrm{pg} / \mathrm{ml}$, while it was $3,611.52 \pm 3,676.73 \mathrm{pg} / \mathrm{ml}$ in the $\mathrm{mild} /$ moderate group, and both were significantly higher than that of the control group ( $p=0.001$ ). Conclusion: In this study, the expression of serum BD-2 was raised in patients with CCHF, and this increase may beneficially affect survival. Studies with larger sample sizes are needed to confirm the association of serum $\mathrm{BD}-2$ with CCHF prognosis.

(c) 2015 S. Karger AG, Basel

\section{Introduction}

Crimean-Congo hemorrhagic fever virus (CCHFV) is a member of the Bunyaviridae family that belongs to the genus Nairovirus. The vectors of CCHFV are ticks that belong to the genus Hyalomma, particularly Hyalomma marginatum [1]. Inflammatory mediators are key elements of the immune response during the course of CCHF infection. Natural killer cell activation, macrophage activation and hemophagocytosis are probable pathological processes in CCHF [2]. Endothelial injury is thought to be caused by the release of proinflammatory cytokines in response to the infection rather than being a direct effect of the virus [2,3]. The CCHFV-induced

\begin{tabular}{ll}
\hline KARGER & $\begin{array}{l}\text { ○ 2015 S. Karger AG, Basel } \\
1011-7571 / 15 / 0252-0163 \$ 39.50 / 0 \quad \text { Karger } \\
\text { E-Mail karger@karger.com }\end{array}$ \\
Thwiccess \\
Thisis an Open Access article licensed under the terms of the \\
Creative Commons Attribution-NonCommercial 3.0 Un- \\
ported license (CC BY-NC) (www.karger.com/OA-license), \\
applicable to the online version of the article only. Distribu- \\
tion permitted for non-commercial purposes only.
\end{tabular}

Dr. Emine Parlak

Department of Infectious Diseases and Clinical Microbiology Atatürk University School of Medicine, University street 2506

TR-25070 Erzurum (Turkey)

E-Mail eparlak1@yahoo.com 
damage of the endothelium activates an intrinsic coagulation cascade and increases thrombocyte adhesion and aggregation, resulting in disseminated intravascular coagulation and multiple organ dysfunction. Hemorrhage is the main cause of death in CCHFV [3].

Small cationic antimicrobial peptides, which are released by several cells, protect the host against attacks from microorganisms. $\beta$-Defensin-2 (BD-2) is mainly synthesized by the skin, respiratory tract and gastrointestinal system cells in response to various stimuli, such as lipopolysaccharides and cytokines. BD-2 levels have been studied in various viral diseases $[2,4]$, but no study has investigated BD-2 levels in CCHF. BD-2 has viral infection-suppressing functions which act via different pathways. For example, BD-2 exhibits antiviral activity by compromising the viral envelope and inhibiting the entry of the virus into the cell [4] by interacting with viral glycoproteins and receptors [4]. It also affects cellular signal pathways involved in viral replication [4].

The purpose of this study was to compare serum BD-2 levels in patients with CCHF and healthy individuals. We also aimed to elucidate the role of BD-2 levels in determining the clinical course of the disease and disease prognosis by comparing patients with mild-moderate and severe $\mathrm{CCHF}$.

\section{Patients and Methods}

\section{Patient Selection}

Patients hospitalized at the Department of Infectious Diseases and Clinical Microbiology, Faculty of Medicine, Atatürk University, Medical School Hospital, between March 2009 and August 2010 were included in the study. All the patients were diagnosed with CCHF according to a real-time reverse transcription polymerase chain reaction (RT-PCR) assay and/or an enzyme-linked immunoabsorbent assay (ELISA) of specimens based on the criteria of Swanepoel et al. [5], the modified criteria of Ergonul et al. [6] and clinical criteria of a poor prognosis $[7,8]$. Sixty patients (34 males and 26 females) and 25 healthy controls ( 14 males and 11 females) were studied. The patients were divided into two groups: those with mild-moderate disease $(n=42)$ and those with severe disease (n $=18$ ). All the patients were living in rural areas or had a history of visiting such areas; of these, 29 were engaged in farming; 18 were housewives, of whom 11 were also engaged in farming; 7 were involved in animal husbandry; 1 was a student, and the remaining 5 were from other occupational groups.

According to the criteria of Swanepoel et al. [5], severe disease is defined as the presence of at least one of the following laboratory values in the first 5 days after the onset of clinical symptoms, while absence of these symptoms indicates mild disease: a blood leukocyte count $\geq 10,000 / \mathrm{mm}^{3}$, thrombocyte count $\leq 20,000 / \mathrm{mm}^{3}$, aspartate aminotransferase (AST) $\geq 200 \mathrm{IU} / \mathrm{l}$, alanine amino transferase $(\mathrm{ALT}) \geq 150 \mathrm{IU} / \mathrm{l}$, activated partial thromboplastin time
(aPTT) $\geq 60$ s or a fibrinogen level $\leq 110 \mu \mathrm{g} / \mathrm{dl}$. Confusion, nuchal rigidity, bleeding from more than one source, prolonged fever, disturbed consciousness, splenomegaly, somnolence, hematemesis, melena, high fever, disseminated intravascular coagulation and kidney failure are clinically recognized criteria for a poor prognosis [8-10]. The patient data (epidemiological, demographic, clinical and laboratory) were recorded on previously prepared forms. The results were compared with values from 25 healthy controls.

\section{Method}

Patient blood specimens were collected on a voluntary basis. Informed consent forms were signed by the patients or their relatives. A 5-ml blood sample was collected from an appropriate peripheral vein immediately after hospitalization. After $30 \mathrm{~min}$, the blood was centrifuged for $5 \mathrm{~min}$ at 2,000 rpm, and the serum was separated by decantation. A $1-\mathrm{ml}$ serum sample was transferred to one tube and $2 \mathrm{ml}$ to another tube. Serum samples $(2 \mathrm{ml})$ were sent to the Refik Saydam Hygiene Center Reference Laboratory in accordance with appropriate transportation norms of the Erzurum Provincial Health Directorate. The patients included in this study had CCHFV confirmed by PCR in the reference laboratory. Twenty-five healthy individuals were enrolled as a control group. The patient and control group sera (in 1-ml tubes) were stored at $-70^{\circ} \mathrm{C}$ until assayed. On the day of the study, the sera were thawed at $+5^{\circ} \mathrm{C}$ in a refrigerator.

Serum AST, ALT, creatine phosphokinase (CK) and lactate dehydrogenase $(\mathrm{LDH})$ levels were measured using original kits (Roche Diagnostics, Mannheim, Germany). Biochemical measurements were performed using standard laboratory methods. Hemogram parameters were determined with the Beckman Coulter LH 780 (Beckman Coulter Ireland Inc./Mervue, Cork, Ireland) device in the laboratory. Hemogram parameters were analyzed using standard biochemical techniques and kits (LH 780). Prothrombin time (PT), international normalized ratio (INR) and aPTT were analyzed using an ACL Top $700^{\circledR}$ (Instrumentation Laboratory, Bedford, Mass., USA).

\section{Measurement of BD-2 Levels}

Serum BD-2 levels were measured using a commercial Phoenix brand ELISA kit (lot No. 602700; Phoenix Pharmaceuticals Inc., Burlingame, Calif., USA). Wells were covered with recombinant anti-human BD-2. A standard or specimen was pipetted into the well to enable BD-2 molecules to bind to anti-human BD-2 antibodies in the stable phase. Conjugate labeled with biotin, another antibody developed against BD-2, was then added, and BD-2 bound to this molecule, resulting in a sandwich structure. Following washing, peroxidase enzyme labeled with streptavidin was added. This enzyme binds to the conjugates marked with biotin. A blue-colored product emerged with the addition of the peroxidase substrate 3,3',5,5'-tetramethylbenzidine. The concentration of BD-2 in the specimen was directly proportional to the intensity of this blue color. In the final stage, a 'stop solution' was added to the wells to halt the reaction catalyzed by peroxidase, turning the color of the solution in the wells from blue to yellow. The density of this color was measured at a wavelength of $450 \mathrm{~nm}$. A standard curve was produced using concentrations corresponding to the absorbance obtained using the same procedure and standards that were obtained from serial dilutions, and the BD-2 concentrations in the specimens were determined using that curve. 
Table 1. Various laboratory findings (means \pm SD and ranges) in surviving and nonsurviving patients

\begin{tabular}{lcc}
\hline & Deceased $(\mathrm{n}=6)$ & Recovered $(\mathrm{n}=54)$ \\
\hline $\mathrm{WBC}, 10^{3} / \mathrm{mm}^{3}$ & $4,640 \pm 2,880(2,700-9,900)$ & $2,278 \pm 1,003(770-6,300)$ \\
$\mathrm{PLT}, \mathrm{n} / \mathrm{mm}^{3}$ & $26,500 \pm 23,450(13,000-73,000)$ & $68,130 \pm 34,861(1,200-151,000)$ \\
AST, IU/1 & $802 \pm 1,112(57-3,000)$ & $217 \pm 345(27-2,413)$ \\
ALT, IU/1 & $253 \pm 319(27-870)$ & $105 \pm 118(16-605)$ \\
$\mathrm{CK}, \mathrm{IU} / \mathrm{l}$ & $912 \pm 550(229-1,853)$ & $634 \pm 659(34-2,408)$ \\
LDH, IU/l & $2,187 \pm 2,340(384-6,496)$ & $582 \pm 467(199-3,186)$ \\
$\mathrm{PT}, \mathrm{s}$ & $17.3 \pm 2.08(15-19.6)$ & $14.4 \pm 1.81(11-19.4)$ \\
$\mathrm{aPTT}, \mathrm{s}$ & $44.7 \pm 5.6(38.6-52.2)$ & $34.6 \pm 5(21.9-50.7)$ \\
$\mathrm{INR}$ & $1.58 \pm 0.27(1.22-1.9)$ & $1.14 \pm 1.18(0.86-1.68)$ \\
\hline
\end{tabular}

Statistical Analysis

Standard data are expressed as numbers, percentages, and means \pm SD. The data were analyzed with IBM SPSS 20.0 (Chicago, Ill., USA) software. Data with a normal distribution were analyzed with the Kolmogorov-Smirnov test. An independent-group Student $t$ test was used to analyze the age of the patient and the control group. Gender distribution within both groups was analyzed using a $\chi^{2}$ test. The mean BD-2 levels at the time of presentation were measured with an independent-group Student t test. BD-2 levels of the mild-moderate, severe and control groups were analyzed with the Kruskal-Wallis test, and two-way comparisons were performed with the Mann-Whitney test. Surviving, nonsurviving and control group BD-2 levels, hemorrhage, altered consciousness and pulmonary findings were analyzed with the Mann-Whitney test. Spearman's correlation analysis of BD-2 levels with ALT, AST, CK, LDH, PT, aPTT, INR, white blood cell (WBC) and platelet (PLT) counts was performed. A p value $<0.05$ was regarded as statistically significant.

\section{Results}

The mean age of the patient group was $50.48 \pm 16.85$ years, while that of the control group was $50.88 \pm 14.85$ years. The sex and gender distributions were similar in both the patient and the control group. Of the 60 patients, 18 (30\%) patients had severe disease, while $42(70 \%)$ had mild-moderate disease. Of the 60 patients enrolled in the study, 6 (10\%) died and $54(90 \%)$ were discharged in a healthy condition.

Of the 60 patients, 45 (75\%) had a history of tick contact while the other 15 (25\%) had no contact with ticks. The mean incubation period in the patients with a known history of contact with ticks was $3.7 \pm 1.5$ days (1-10 days).

Blood from the patients was collected $3.2 \pm 1.5$ days (mean; range 1-7 days) after the onset of symptoms. The most common symptoms were fever (97\%), lethargy
(95\%) and loss of appetite (80\%). Hemorrhage was observed during hospitalization or at subsequent follow-ups in $13(22 \%)$ patients, most commonly from the gums $(8 \%)$ and nose (8\%). Melena was present in $1(2 \%)$ patient during hospitalization.

\section{Physical Examination}

The most common findings of physical examination in the patients were facial hyperemia (62\%); $55 \%$ had hyperemia in the oropharyngeal mucosa and $38 \%$ had conjunctival hyperemia. Severe hemorrhage developed in 6 (10\%) of the patients during monitoring. Four of these patients died, and the other 2 were discharged in a healthy condition. Rectus muscle bleeding was observed in $1(2 \%)$ patient, and hemarthrosis in another patient. Radiologically, panbronchiolitis was seen in 1 patient, and widespread pneumonic infiltration was observed in 2 others who died. Bradycardia was observed in $3(5 \%)$, who were discharged in a healthy condition. Atrial fibrillation developed in 1 (2\%) patient, who subsequently died. The laboratory values of the patients are shown in table 1 .

There was no significant association between patient age and BD-2 values $(p=0.761)$. There was also no significant difference between the BD-2 levels in males $(3,757.69 \pm 3,428.04 \mathrm{pg} / \mathrm{ml})$ and females $(4,732.95 \pm$ $4,543.26 \mathrm{pg} / \mathrm{ml} ; \mathrm{p}=0.347)$. BD-2 levels were lower in deceased patients $(1,529.81 \pm 1,028.14 \mathrm{pg} / \mathrm{ml})$ than in survivors $(4,474.80 \pm 4,041.58 \mathrm{pg} / \mathrm{ml})$, but the difference was not significant $(\mathrm{p}=0.055)$. Analysis of BD-2 levels according to the day of symptom onset showed no significant difference between onset on days 1-3 and 4-7 ( $\mathrm{p}=$ $0.667)$. In the severe group, $\mathrm{BD}-2$ levels were higher $(5,507.45 \pm 4,327.06 \mathrm{pg} / \mathrm{ml})$ than those in the mild-moderate group $(3,611.52 \pm 3,676.73 \mathrm{pg} / \mathrm{ml})$, although the difference was not statistically significant $(p=0.088)$. A 
Table 2. Comparison of BD-2 levels in the patient and controls

\begin{tabular}{|c|c|c|c|}
\hline & \multicolumn{2}{|l|}{ Patient subgroups } & \multirow[t]{2}{*}{ Control group } \\
\hline & severe & mild-moderate & \\
\hline $\mathrm{n}$ & 18 & 42 & 25 \\
\hline $\mathrm{BD}-2, \mathrm{pg} / \mathrm{ml}$ & $5,507.45 \pm 4,327.06^{\mathrm{a}}$ & $3,611.52 \pm 3,676.73^{\mathrm{a}, \mathrm{b}}$ & $964.45 \pm 266.07$ \\
\hline
\end{tabular}

Table 3. Correlation between serum BD-2 levels and simultaneously investigated laboratory test results

\begin{tabular}{lcrl}
\hline Parameter & Mean \pm SD (range) & \multicolumn{2}{l}{$\mathrm{BD}-2$} \\
\cline { 3 - 4 } & & $\mathrm{R}$ & $\mathrm{p}$ \\
\hline WBC & $2,514.5 \pm 1,455.4(770-9,900)$ & -0.414 & 0.001 \\
PLT & $63,966.67 \pm 36,012.7(12,000-151,000)$ & -0.082 & 0.531 \\
AST & $275.17 \pm 492.8(27-3,000)$ & 0.314 & 0.015 \\
ALT & $120.17 \pm 152.4(16-870)$ & 0.247 & 0.057 \\
CK & $662.12 \pm 654(34-2,804)$ & 0.011 & 0.935 \\
LDH & $742.58 \pm 946.6(199-6,496)$ & 0.294 & 0.023 \\
PT & $14.688 \pm 2(11-19.6)$ & -0.138 & 0.293 \\
aPTT & $35.63 \pm 6.7(21.9-52.2)$ & 0.037 & 0.781 \\
INR & $1.1857 \pm 0.2(0.86-1.9)$ & -0.139 & 0.290 \\
\hline
\end{tabular}

comparison of serum BD-2 levels in patients with or without hemorrhage $(\mathrm{p}=0.120)$ and those with or without existing pulmonary auscultation findings $(\mathrm{p}=0.487)$ revealed no significant association. In patients with or without altered consciousness, the difference in BD-2 levels did not reach the threshold for statistical significance $(\mathrm{p}=0.066)$.

The mean serum BD-2 levels were significantly higher in the patient group than in the control group $(4,180.30$ $\pm 3,944.19$ vs. $964.45 \pm 266.07 \mathrm{pg} / \mathrm{ml} ; \mathrm{p}=0.001$ ).

The serum BD-2 value of the control group was significantly lower $(964.45 \pm 266.07 \mathrm{pg} / \mathrm{ml})$ than in any of the patient groups ( $\mathrm{p}=0.001$ for both groups; table 2 ).

The results of correlation analyses of associations between the laboratory parameters (WBC, PLT, AST, ALT, CK, LDH, PT, aPTT and INR) and serum BD-2 levels are shown in table 3 . There was a moderately significant negative correlation between BD-2 levels and WBC ( $\mathrm{p}=$ 0.001 ), and a moderately significant positive correlation between BD-2 levels and AST and LDH ( $\mathrm{p}=0.015$ for AST and $p=0.023$ for $\mathrm{LDH}$ ). No correlation was determined between serum BD-2 levels and ALT, PLT, CK, PT, aPTT or INR.

\section{Discussion}

This study revealed significantly higher serum BD-2 levels in patients with CCHF compared with the healthy control group. These levels were remarkably raised in the severe patient group and increased in the mild-moderate group, but lower in nonsurviving than in surviving patients, and higher than in the control group. BD2 release may be increased to overcome severe disease. Patient serums were taken at different time points. The number of patients with severe disease is lower than the numbers for patients with mild-moderate disease and controls. In order to be able to generalize data, further studies evaluating immunological parameters, viral load and other defensins together are needed. Thus, it may be suggested that CCHFV may increase BD-2 release, supporting the findings of existing studies [11-14]. The results seem to show that increased BD-2 has a positive effect on the survival of patients with CCHF. However, it is difficult to generalize the findings due to the low patient numbers in this study. Serum BD-2 levels were positively correlated with serum AST and LDH levels in the surviving patients in the severe patient group. The positive correlation between $\mathrm{BD}-2$ levels and these enzymes suggests that the protection provided by BD-2 may increase in accordance with the levels of these protein with progressing infection. As with some other viral diseases, CCHF progresses with leukopenia. We found a negative correlation between the WBC count and serum BD-2 levels in our patient group. This suggests that increased expression of BD-2 accompanies leukopenia in patients with CCHF.

The viruses responsible for viral hemorrhagic fever are thought to alter the hemostatic mechanism through two separate pathways: direct hemostasis and indirect immunological and inflammatory effects $[1,9,15-18]$. Patients with viral hemorrhagic fever exhibit inappropriate immune responses, resulting in elevated viremia and increased proinflammatory cytokine levels in the late stage of the disease $[15,19]$. A compromised immune system has also been observed in severe cases of CCHF [17, 20, 
21]. In CCHF, reduced mononuclear cell infiltration occurs in areas of intense hepatocellular injury, whereas increased infiltration occurs in areas with less injury. The absence of a significant inflammatory response in infected and injured hepatocytes among patients with CCHF shows that the damage derives directly from the cytopathic effect of the virus [19]. In a previous study, serum transaminases were significantly elevated in association with liver injury [19]. In the present study, the mean ALT and AST of the nonsurviving patients were significantly higher than those of the survivors.

BD has a suppressive effect on viral and bacterial infections, which is exerted via various pathways. The expression of BD-2 increases in epithelial cell cultures in response to interleukin- $1 \alpha$ and $-1 \beta$, tumor necrosis factor- $\alpha$, interferon- $\gamma$, Gram-negative bacteria, Candida albicans, Mycobacterium tuberculosis and bovis, lipopolysaccharides and lipoarabinomannan [4].

Significant levels of BD-2 were released in several viral infections. BD-2 has been shown to play a protective role in viral infections of the respiratory system. Synthesis of BD-2 and BD-3 was also reported to increase in bronchial epithelial cells in Rhinovirus infections [14]. It has also been shown to suppress infection in human influenza $\mathrm{A}$, Rhinovirus and respiratory tract infections. BD-2 also exhibited a very powerful in vitro antiviral effect against influenza A virus infection [12,13].

Several studies have investigated the therapeutic effect of $\mathrm{BD}$ due to their ability to kill various infectious agents and their immunoregulating effects. The administration of molecules by topical or systemic routes that stimulate $\mathrm{BD}$ synthesis is a reliable and economical therapeutic option [4]. Support therapy represents the basis of treatment in CCHF. Acetylsalicylic acid, nonsteroidal anti-inflammatory drugs and anticoagulant therapy are contraindi- cated. Intramuscular injections should be avoided $[1,22]$. In the present study, all the patients received support therapy. We suggest that BD-2 can be included among the treatment modality options.

The aim of the present study was to elucidate the role of BD-2 in CCHF and to draw attention to the interaction between the adaptive and innate immune systems. To better understand the role of BD-2 in the pathogenesis of $\mathrm{CCHF}$, its prognostic value and its treatment effect, further studies are needed. Such studies should simultaneously examine all immunological parameters, viral load and serum BD-2 values in addition to changes in these parameters during the various stages of the disease. However, data to support this idea are lacking in the literature. Based on our clinical observations, we think that such a study of the pathogenesis would fill an important gap in the literature. The findings of the current study should be of use in guiding subsequent work and of benefit in the diagnosis and treatment of this disease, for which there is currently no effective treatment. BD-2 may be useful in the treatment of this disease in the future.

\section{Conclusion}

In this study, serum BD-2 expression was increased in the patient group compared to healthy subjects. This increase may be helpful in survival. Studies including a larger sample size are needed to confirm the association of serum $\mathrm{BD}-2$ with $\mathrm{CCHF}$ prognosis.

\section{Disclosure Statement}

No conflicts of interest.

\section{References}

1 Ergonul O: Crimean-Congo haemorrhagic fever. Lancet Infect Dis 2006;6:203-214.

2 Whitehouse CA: Crimean-Congo hemorrhagic fever. Antiviral Res 2004;64:145-160.

3 Akıncı E, Bodur H, Leblebicioglu H: Pathogenesis of Crimean-Congo hemorrhagic fever. Vector Borne Zoonotic Dis 2013;13:429_ 437.

4 Guaní-Guerra E, Santos-Mendoza T, LugoReyes SO, et al: Antimicrobial peptides: general overview and clinical implications in human health and disease. Clin Immunol 2010; 135:1-11.
5 Swanepoel R, Gill DE, Shepherd AJ, et al: The clinical pathology of Crimean-Congo hemorrhagic fever. Rev Infect Dis 1989;11:794-800.

-6 Ergonul O, Celikbas A, Baykam N, et al: Analysis of risk-factors among patients with Crimean-Congo haemorrhagic fever virus infection: severity criteria revisited. Clin Microbiol Infect 2006;12:551-554.

7 Ozkurt Z, Kiki I, Erol S, et al: Crimean-Congo hemorrhagic fever in Eastern Turkey: clinical features, risk factors and efficacy of ribavirin therapy. J Infect 2006;52:207-215.
8 Jamil B, Hasan RS, Sarwari AR, et al: Crimean-Congo hemorrhagic fever: experience at a tertiary care hospital in Karachi, Pakistan. Trans R Soc Trop Med Hyg 2005;99:577-584.

-9 Ergonul O: Crimean-Congo hemorrhagic fever virus: new outbreaks, new discoveries. Curr Opin Virol 2012;2:215-220.

-10 Bakir M, Ugurlu M, Dokuzoguz B, et al: Crimean-Congo haemorrhagic fever outbreak in Middle Anatolia: a multicentre study of clinical features and outcome measures. J Med Microbiol 2005;54:385-389. 
11 De Smet K, Contreras R: Human antimicrobial peptides: defensins, cathelicidins and histatins. Biotechnol Lett 2005;47:1333713347.

12 Meyer-Hoffert U, Schröder JM, Schwarz T, et al: Increased expression of human beta-defensin 3 in molluscum contagiosum. Clin Exp Dermatol 2010;35:190-192.

13 Gong TX, Jiang Y, Wang YL, et al: Recombinant mouse beta-defensin 2 inhibits infection by influenza A virus by blocking its entry. Arch Virol 2010;155:491-498.

14 Proud D, Sanders SP, Wiehler S: Human rhinovirus infection induces airway epithelial cell production of human beta-defensin 2 both in vitro and in vivo. J Immunol 2004;172: 4637-4645.
15 Mammen EF: Disseminated intravascular coagulation. Clin Lab Sci 2000;13:239-245.

16 Ergonul O, Tuncbilek S, Baykam N, et al: Evaluation of serum levels of interleukin (IL)6, IL-10, and tumor necrosis factor-alpha in patients with Crimean-Congo hemorrhagic fever. J Infect Dis 2006;193:941-944.

17 Chen JP, Cosgriff TM: Hemorrhagic fever virus-induced changes in hemostasis and vascular biology. Blood Coagul Fibrinolysis 2000;11:461-483.

18 Burt FJ, Swanepoel R, Shieh WJ, et al: Immunohistochemical and in situ localization of Crimean-Congo hemorrhagic fever (CCHF) virus in human tissues and implications for CCHF pathogenesis. Arch Pathol Lab Med 1997;121:839-845.
9 Ardalan MR, Tubbs RS, Chinikar S, et al: Crimean-Congo hemorrhagic fever presenting as thrombotic microangiopathy and acute renal failure. Nephrol Dial Transplant 2006; 21:2304-2307.

20 Shepherd AJ, Swanepoel R, Leman PA: Antibody response in Crimean-Congo hemorrhagic fever. Rev Infect Dis 1989;4:801-806.

21 Geisbert TW, Hensley LE, Larsen T, et al: Pathogenesis of Ebola hemorrhagic fever in cynomolgus macaques: evidence that dendritic cells are early and sustained targets of infection. Am J Pathol 2003;163:2347-2370.

22 Ju SM, Goh AR, Kwon DJ, et al: Extracellular HIV-1 Tat induces human beta-defensin-2 production via NF-kappaB/AP-1 dependent pathways in human B cells. Mol Cells 2012;33: 335-341. 